\title{
Large-Scale Promotion of Animal Dung-based Domestic Biogas Digesters through Public Private Partnership: A Successful Case of Nepal
}

Govind Raj Pokharel and Arjun Bahadur Chettri

Abstract: Large-scale promotion of small scale decentralized renewable energy technologies to achieve a part of millennium development goal remained a great challenge until recently. However, a properly implementation of a public private partnership applied in biogas sector in Nepal has shown that scaling up of small scale renewable energy technologies is feasible if a multi-stakeholder sector development approach and favorable policy as well as modality is adopted. Nepal's biogas program has been instrumental in helping to achieve some of the Millennium Development Goals (MDGs) by creating economic and social development opportunities in a sustainable way. Such model could also be widely replicated in any other renewable energy technologies and other continent of the world.

Key words: Animal Dung Based Biogas Digester, Dome type Biogas Plant, Nepal

\section{Background}

More than 86\% of the people of Nepal use fuelwood for cooking. Nepal's per capita energy consumption is 353 $\mathrm{kg}$ of oil equivalent (KoE) and almost $96.7 \%$ of the energy consumed in residential sector comes from traditional resources like fuelwood, agriculture residue and animal dung (WECS 2010). The domestic sector consumes more than $89 \%$ of the total primary energy consumption in Nepal (WECS, 2010); that is, major energy is consumed by cooking activities. These cooking fuels are usually gathered by women and children, denying them time that might otherwise be spent on productive activities or at school. In addition, by burning traditional fuels at home, women and small children are exposed to smoke equivalent of 2000 g-C per day (e.g. Todaro and Smith 2003) and are prone to respiratory illnesses and eye ailments.

In terms of energy distribution and consumption, energy poverty in Nepal is widespread as most of families in rural areas are still waiting to have access to clean energy either for cooking, lighting or for productive uses. They are not able to have minimum energy required per capita as defined by energy poverty level; i.e., $40 \mathrm{KoE}$ per year for cooking and $10 \mathrm{KoE}$ per year for lighting (Modi et al 2005). Energy is necessary for daily survival (WCED 1987: 168). The minimum energy required for Nepalese people especially in the hills is about 129.25 KoE for cooking, $72.62 \mathrm{KoE}$ for water boiling and 35.77 $\mathrm{kWh}$ for lighting per year per household (PS/Nepal 2009). According to Goldemberg (1996), energy consumption for a normal living standard for a person is, on average, about 1000 to $1300 \mathrm{KoE}$. The sustainable annual yield of fuelwood in Nepal is theoretically 12.51 million tons (WECS 2010). This shows that the per capita sustainable fuelwood is less than $445 \mathrm{~kg}$ per year, which is less than 0.178 tons of oil equivalent (TOE).
This is far below the energy poverty level defined as per Modi et al.

The majority of Nepalese farmers have livestock, normally one or two buffalo and at least two oxen. The total livestock (cattle and buffalo) population in Nepal is about 10.4 million. The available animal dung is either burnt directly as solid biomass for energy or used as fertilizer for agriculture fields. Domestic biogas plants are, therefore, a sustainable solution for households with livestock, and about 1.3 to 2.9 million domestic bio-

\begin{tabular}{|llll}
\hline \multicolumn{2}{|l}{ Items } & Units & Amount \\
\hline 1. & Average Cattle dung feeding & $\mathrm{Kg} /$ day & $36-45$ \\
\hline 2. & Average water mix in feeding & Liters/day & $36-45$ \\
\hline 3. Average daily gas production & $\mathrm{m}^{3}$ & 1.44 \\
\hline 4. Average stove burning hours & Hours & 3.6 \\
\hline 5. Average daily energy production & $\mathrm{MJ}$ & 27.35 \\
\hline
\end{tabular}

Table 1. Input to and Output from a 6 Cubic Meter Biogas Plant (compiled from Karki et al 2009)

gas plants can be installed in Nepal (Karki et al 2009). Technically, however, biogas is an effective and feasible means of alternative energy with a potential of 1.5 million biogas plants in Nepal (Mendis and van Nes 1999, Gautam et al 2009). Nepal started as early as 1970 s to utilize the multiple benefits from animal dung with a sustainable approach, although Nepal has over a half century of history of biogas promotion starting with an experimental biogas plant constructed in 1955 (Karki et al 2009, Bajgain and Shakya 2005).

\section{Biogas Technology}

The fixed dome type biogas digesters are popularly used in Nepal, adapted and revised from a Chinese design made suitable to Nepalese conditions (Karki et al 
2009). The basic materials required for construction are cement, stone or bricks, iron rods, aggregates, sand, burners, and lamps. These types of digesters can be made locally where most of the construction materials are available.

The digesters convert animal dung, human excrement and various other organic materials at the household level into a combustible methane gas (50-70\% methane, 30-40\% CO2, 5-10\% hydrogen and others, according to Karki et al 2009) in large portion known as biogas, which can be used in simple gas stoves for cooking and in lamps for lighting. Table 1 provides a glance at total input and output from a typical $6 \mathrm{~m}^{3}$ biogas plant in Nepal. Approximately 36-45 kg/day of dung mixed with equal amount of water produces approximately 27.35 produced from burning firewood and kerosene. It also contributes to the reduction of greenhouse gas emissions by approximately 4.84 tons of $\mathrm{CO} 2$. And potential employment generated by a biogas plant is, on average, 1.55 people-years for skilled people in the construction, maintenance, marketing, and financing of biogas plants (UNFCC 2005). (According to UNFCC (2005), about 9,708 biogas plants reduces 328,900 tons of $\mathrm{CO} 2 \mathrm{e}$, and generates 15,000 person-year potential employment opportunity; the per plant figure is calculated on this basis.) BSP/N (2009) reports that approximately 9,000 people are employed in the biogas sector in Nepal.

Moreover, the residual biological slurry from the biogas plants can be used as superior organic fertilizers to enhance agricultural yields (UNFCC 2005) thereby re-
Millennium Development Goals (MDGs)

Eradicate extreme poverty and hunger

Achieve universal primary education

Promote gender equality and empower women

Reduce child mortality

Improve maternal health

Combat HIV/AIDS, malaria and other diseases

Ensure environmental sustainability
Domestic Biogas Construction
Through employment and increased agriculture yield, improved sanitation and integrated animal husbandry practices.

Direct impact through reduced drudgery (time collecting firewood, for example, especially for girls, as well as access to brighter light).

Reduces the burden of collecting firewood on women and allows the alternative allocation of precious time of, in particular, the female members of the household, opportunities in the development of biogas burners, lamps and refrigerators locally.

Reduced air pollution, associated respiratory diseases and accidents from open fire, improved sanitation and hygiene education, reduced parasitic infections, diarrhoea and other water and vector-borne diseases.

Direct impact through reduced drudgery, improved indoor environment, etc.

Biogas stoves replace conventional cook stoves and energy sources, virtually eliminating indoor smoke pollution and, hence, the related health risks (e.g., respiratory and eye diseases, burning accidents of women and children).

Reduced deforestation and desertification, controlled GHG emission from livestock and organic waste disposal, and recycled nutrients and restored soil fertility.

Table 2. Impact of Scaling up of Biogas Technologies in Millennium Development Goals (compiled from BSP/N 2008 and 2009, Mendis and van Nes 1999, Bajgain and Shakya 2005, GFA 2009, Karki et al 2009).

megajoule of energy for daily use, which is equivalent to 3.6 to 4 stoves hours.

\section{Benefits of Biogas}

Biogas plants reduce time and labor of wood collection, cleaning of pots and the actual cooking process (Karki et al 2009). The workload reduction provides other opportunities. Workload per household (mainly women) has been reduced by three hours a day (Mendis and van Nes 1999). Because of methane capture, Biogas is also reducing the emission of green house gases. Each biogas plant, on average, saves about 3000 $\mathrm{kg}$ of firewood and 38 liters of kerosene consumption annually (ibid.) and saves an equivalent amount of $\mathrm{CO}_{2}$ duce the use of synthetic fertilizer and $\mathrm{CO} 2$ emissions from its life cycle of the synthetic fertilizer manufacturing process. Due to reduction of indoor air pollution, a biogas digester offers improvements in respiratory health and reductions in eye problems, especially of women and children who cook food normally in developing countries. In addition, improved hygienic conditions are achieved with improved sanitation practices through attachments of toilets to biogas plants, as $72 \%$ of all biogas plants have attached toilets.

Development of biogas technologies in Nepal has contributed significantly to help meet the Millennium Development Goals (MDGs). Table 2 explains how 


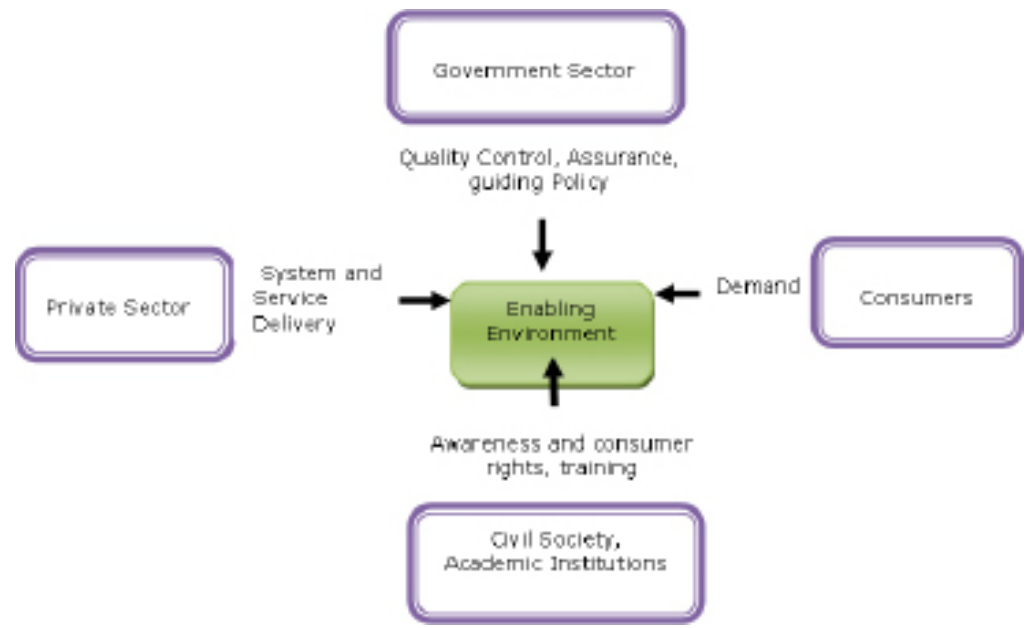

Figure 1. Multi-Stakeholder Approach Based on the Public Private Partnership Model in Up-Scaling Domestic Biogas Digesters in Rural Nepal est challenges such as renewable energy development. USAID (2009) developed public private partnership model to promote clean energy access, expand access to energy, finance energy projects, create favorable and enabling environments, and train energy professionals.

Nepal's Rural Energy Policy, 2006 was targeted to promote renewable energy mainly to reduce dependency on traditional energy and to conserve the environment by increasing access to clean and cost effective energy in the rural areas, and to increase employment opportunities and productivity through the development of rural energy resources. Under this policy, the goal was to improve livelihoods of the populadomestic biogas technology promotion in Nepal has contributed in achieving the Millennium Development Goals in Nepal.

\section{Millennium Development Goals (MDGs) Domestic Biogas Construction}

Eradicate extreme poverty and hunger Through employment and increased agriculture yield, improved sanitation and integrated animal husbandry practices.

Achieve universal primary education Direct impact through reduced drudgery (time collecting firewood, for example, especially for girls, as well as access to brighter light).

\section{Enabling Environment in the sector}

The promotion program is firmly centered on a successful public private partnership model that works to enhance the capacities of the entire biogas sector rather than individual stakeholders (Figure 1). In addition to the government, local NGOs, and small and medium scale biogas companies/enterprises are the main actors in supplying sustainable solutions to the demanding households in rural areas. The public private partnership modality has established the government-enabled market-based approach in renewable energy promotion activities in Nepal. An even more innovative approach involves collaboration among three development players; i.e., government, private sector and civil society, that exist for complementarities and synergy. The supply system is based on market demand and all players have a great role in generating demand. The government facilitates the supply-demand game, whereas civil society and academic institutions make consumers aware of the benefits, quality concerns and training skilled human resources to successfully implement biogas projects. In this way, an enabling environment has been created.

Rightly done, public private partnerships are powerful tools to provide enduring solutions to some of our great- tion by integrating renewable energy with social and economic activities (GON 2006). The policy has also helped to create a favorable environment for the sector. Even before the rural energy policy was promulgated, the Nepal government provided interest free loans to interested farmers willing to install domestic biogas units as early as FY1975/76 (Karki et al 2009). Since The Eighth Five Year Development Plan (NPC 1992), the government has provided a promotional subsidy, which covers around $20-30 \%$ of total up-front investment of a plant.

About 85 biogas companies and 16 component manufacturing workshops are involved in the service and technology promotion, installation through their private business model (BSP/N 2009). In 2005 there were 60 companies (UNFCC 2005). Local GOs, NGOs, CBOs are involved for equitable market development and promotion of biogas even in areas beyond private sector's ability to reach. Development banks, microfinance institutions and rural cooperatives are actively playing their role for the provision of credit to co-finance

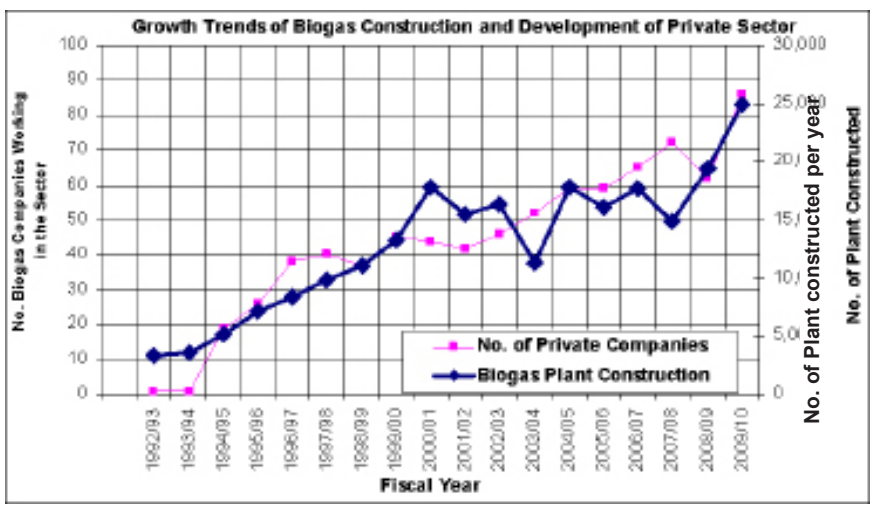

Figure 2. Trend of Private Companies Involved and Plant Construction in Nepal (Source BSP/N 2009)

farmers' biogas purchases. Nepal's biogas program represents a successful public private partnership which has altogether installed over 200,000 biogas plants in 72 districts across Nepal (BSP/N 2009) (Figure 2). 


\section{Up-scaling trend of Biogas Technology in Nepal}

As a first milestone in the development history, a public sector company was established already in 1977 to promote the technology. Government has targeted to install about 4,00o biogas plants already in its seventh five year plan during 1985-1990 (NPC 1987). However, the ambitious target could not be reached without a matured sector and a functioning and enabling environment. As benefits of biogas were gradually realized by the users, local bodies and policy makers, capacity of the sector was also growing as supply side was becoming vibrant with growing market demands. Only in 1996 after having lesson learned from the biogas sector, however, did government establish a nodal agency to coordinate all activities and stakeholders and harmonize isolated projects to adopt the sector development approach in other Renewable Energy (RE) promotion activities. A promotion modality based on the public private partnership approach has matured in the biogas sector, and has been applied to other RE sectors. National level policy to promote wider scale renewable energy increased after several learning experiences only in 2006. By 2008, decentralized renewable energy technology reached $7 \%$ of the population of the country with clean energy (GON 2008). Decentralized domestic small scale biogas alone is now producing more than $420 \mathrm{MW}$ of thermal power from around 220,000 installed units as "the power equivalent of the installed biogas plants ranges from $1.16 \mathrm{KW}$ to $2.32 \mathrm{KW"} \mathrm{(UNFCC} \mathrm{2005).}$

The up-scaling trend was achieved only with a robust, quality ensuring mechanism tied up with incentives. The subsidy given to the farmers is actually a quality ensuring discount which is combined with compulsory after sale services. The mechanism is designed in such a way that it continues as "service against fee" principle. Developing such supporting policy framework is key to achieving scale-up renewable technologies (Li 2009).

The main impacts of the current biogas development model in Nepal are that it offers (a) uniform design of the biogas plants in the country, (b) there is thorough quality control, monitoring and after sales services, (c) the generation of public awareness and outreach to users, and (d) financial support in the form of subsidy (that is tied up with quality ensuring mechanism). One of the most important benefits is that it helps reduce various health problems such as respiratory diseases, eye diseases, asthma and lung problems. Since biogas plants have already been supplied in many accessible areas, it is anticipated that a higher share of biogas plants will be sold to remote and poorer communities. With a strategy of gradually phasing out Nepal government subsidies these people may not be able to contribute their portion; hence, access to micro-financing, developing suitable financing mechanism and awareness of health benefits can significantly help scale-up biogas development to higher level in Nepal.

\section{Functionality of Biogas Technology}

As per Karki et al (2009) more than 95\% are functioning after 3 years of installation, and 94\% users are satisfied with the plant they installed. A biogas users survey was carried out by Alternative Energy Promotion Center (AEPC), a government agency through independent consultant for CDM registered Biogas Project-1 in 2009. A total of 510 biogas plants ( $5 \%$ of the 9,708 registered plants) installed from November 1, 2003 to June 15, 2004 in 25 districts were taken as sample. The survey findings are as follows:

- About 80.82\% biogas user households reported that plants were producing gas smoothly, while the remaining $19.18 \%$ households reported that the plants were not producing gas continuously.

- Among the sample biogas user households, 39.22\% were connected with toilets.

- On the level of satisfaction, out of the total biogas user households surveyed 90.89\% users were satisfied.

- In addition, $2 \%$ of the biogas user households were also using the biogas lamps, and most lamp users were satisfied with their lighting performance.

As sector matures and grows, however, plant quality improves because of the users' level of awareness and competition among the companies. A Biogas Users Survey is carried out annually in Nepal, by independent parties. Consecutive surveys show that biogas plants installed after 2005 are functioning in larger percentage. In totality, around $94-98 \%$ of plants are operating, around $63-69 \%$ plants have a toilet connection, and around 74$86 \%$ users of use the slurry (as liquid or after drying) for composting. Altogether, around $91 \%$ of biogas users are satisfied with the plants they have installed.

\section{Conclusions}

More than 200,000 biogas digesters have been installed in Nepal. The lessons that are useful for up-scaling of small scale decentralized renewable energy technologies, particularly domestic biogas, are these:

- Any financial incentives to the technology need to be tied up with functionality performance of system.

- Government should not directly interfer in the implementation activities of private sectors, but should limit its role to support the enabling environment.

- The quality of supplied services, after sale services and technology need to be ensured through provided incentives.

- Sector building activities like capacity enhancing, awareness raising, and linking with other sector development activities like forestry and agriculture are needed to bring synergy to generate more demands of technology.

- Reliable functionality and ensured quality of the systems is the pre-requisite for up-scaling in large numbers.

- Adequate and suitable financing mechanism needs to be developed where micro-finance or local banks 
can play important role in supporting users financing capability.

Govind Raj Pokharel, PhD, took his degree in Energy Economics from Germany (2004), and has a BE in Mechanical Engineering from India, with 15 years experience in academics and research. Dr. Pokharel has worked as Executive Director of the Alternate Energy Promotion Center(AEPC) from 2006 to 2008. His areas of interest include renewable energy financing, policy, and implementation strategies. Presently, he is working as Associate Professor of Mechanical Engineering in Nepal's Tribhuwan University and is a Senior Advisor to SNV.

Corresponding address: grpokharel@yahoo.com

Arjun B. Chhetri is a Ph.D. candidate in Sustainable Energy in Civil and Resources Engineering in Dalhousie University in Halifax, Canada where his research is on development and characterization of biodiesel fuel from different feed stocks as an alternative transportation fuel in Nepal. Mr. Chhetri holds a Master of Engineering Degree in Energy Technology from Asian Institute of Technology, Thailand.

Corresponding address: kcarjun@gmail.com

\section{References}

Bajgain, S. and I. Shakya (Sthapit), 2005, The Nepal Biogas Support Programme: A Successful Model of Public Private Partnership for Rural Household Energy Supply, Kathmandu: Biogas Sector Partnership-Nepal (BSP/N), SNV/Netherlands Development Organization.

BSP/N, 2007, Biogas Support Programme (BSP) Year Book 2007, Kathmandu: Biogas Sector Partnership-Nepal (BSP/N), SNV/Netherlands Development Organization.

BSP/N, 2008, Biogas Support Programme (BSP) Year Book 2008, Kathmandu: Biogas Sector Partnership-Nepal (BSP/N), SNV/Netherlands Development Organization.

BSP/N, 2009, Biogas Support Programme (BSP) Year Book 2009, Kathmandu: Biogas Sector Partnership-Nepal (BSP/N), SNV/Netherlands Development Organization.

De Alwis, A., 2002, 'Biogas: A review of Sri Lanka's performance with a renewable energy technology,' Energy for Sustainable Development 1: 30-37.

Gautam, R., S. Baral and S. Herat, 2009, 'Biogas as a sustainable energy source in Nepal: Present status and future challenges,' Renewable and Sustainable Energy Reviews 13:248-252.

GFA, 2009, Mini Biogas Plants for Households', PoA CDM Manual (from the study 'PoA Concept Development for the Use of Biogas Installations in Small and Medium Sized Pig Farms for a Decentralised Energy Supply in Vietman), CD4CDM Working Paper No.8, UNEP RISØ Center, Germany: GFA Envest; URL: www.cd4cdm.org/Publications/ PoAManualBiogasHouseholds.pdf.

Goldemberg, Jose, 1996, Energy, Environment and
Development, UK: Earthscan.

GON, 2009, Economic Survey 2009, Kathmandu: Ministry of Finance, Nepal.

Karki A.B., J.N. Shrestha, S. Bajgain and I. Sharma, eds., 2009, Biogas as Renewable Source of Energy in Nepal: Theory and Development, Kathmandu: Biogas Sector Partnership-Nepal (BSP/N), SNV/ Netherlands Development Organization.

Li, J., 2009, 'Scaling up concentrating solar thermal technology in China,' Renewable and Sustainable Energy 13(8):2051-2060.

Mendis, Matthew S. and Wim J. van Nes, 1999, The Nepal Biogas Support Programme, Elements for Success in Rural Household Energy Supply, Policy and Best Practice, Document 4, The Netherlands: Ministry of Foreign Affairs.

Modi, V., S. McDade, D. Lallement and J. Saghir, 2005, Energy Services for the Millennium Development Goal (Millennium Project), New York: UNDP, the World Bank and Energy Sector Management Assistance Program (ESMAP).

NPC, 1987, The Seventh Five Year Plan 1985-1990, Kathmandu: National Planning Commission.

NPC, 1992, The Eight Five Year Plan 1992-1997, Kathmandu: National Planning Commission.

PA/Nepal, 2009, Study to Determine Outline Plans for Eliminating Energy Poverty in Nepal, Kathmandu: Practical Action Nepal Office; URL: www.practicalaction.org.uk/file/Energy\%2oPoverty\%20Study_ Unpublished\%20version.pdf.

SNV, 2009, Viable Domestic Biogas Programmes: Success Factors in Sector Development; URL: www.snvworld.org/en/ourwork/Pages/Building viable_domestic_biogas_programmes.aspx.

Todaro, Michael and Stephen Smith, 2003, Economic Development (8th ed.), Delhi: Pearson Education Singapore Pvt. Ltd.

UNFCC, 2005, Biogas Support Program-Nepal (BSP/ Nepal) Activity 1, Clean Development Mechanism Simplified Project Design Document For SmallScale Project Activities (SSC-CDM-PDD), ver. 02; UN Framework Convention on Climate Change/ CDM-Executive Board; URL: http://cdm.unfccc. int/UserManagement/FileStorage/A4NYD8EXQY928HD61LHWHEIM82MBIN.

UNIDO, 2009, 'Scaling up renewable energy in Afri$c a$ ', paper presented at the 12th Ordinary Session of Heads of State and Governments of the African Union, Addis Ababa, Ethiopia, prepared by United Nations Industrial Development Organization, Vienna.

USAID, 2009,. Guide for Global Development Alliance, Building Alliance Series: Energy, Washington DC: U.S. Agency for International Development.

WCED, 1987, Our Common Future, Oxford, UK: Oxford University Press for the World Commission on Environment and Development.

WECS, 2010, Energy Synopsis Report, Nepal 2010, Kathmandu: Water and Energy Commission Secretariat, Ministry of Energy. 